\title{
Is it possible to define architectural identity more objectively?
}

\author{
Malathe Hamid ${ }^{1,}$ Laura Hanks ${ }^{2}$ and Wang $\mathrm{Qi}^{3}$ \\ 1,2\&3 University of Nottingham, Nottingham, UK
}

\section{Keywords}

Architectural identity; KCC, complexity, ambiguity, experiential qualities, objective

\begin{abstract}
The concept of identity is complex and at the same time ambiguous. Architectural identity, however, is even more complex. This stems from the fact that architecture is the mirror that reflects the different political, cultural, social and economic factors that are shaping the city.

In this research, Khartoum, the capital of Sudan is chosen as a case study to explore its contemporary architectural identity. Initial findings from interviewing different parties in the city including architects, academicians and planners highlighted the significant conflict in expressing the Sudanese architectural identity in the contemporary architecture. This resulted in a total disregard in considering it in both urban and architectural design processes. While the majority of interviewed participants realised this, only a few undertook certain design approaches to confront it.

Therefore, this research argues that it is necessary to confront the ambiguity of architectural identity by simplifying its complexity. In order to achieve this, simpler topics such as the architectural character and architectural features are introduced then explored as ways to interpret architectural identity more objectively. It could be concluded that addressing the complexity of architectural identity will provide important answers for the future of any contemporary architecture including that of Khartoum.
\end{abstract}

\section{Is it possible to define identity?}

The early exploration of this research has commenced with the hypothesis that architectural identity could be precisely identified. Within this, general definitions of the term identity were explored. According to the Oxford English Dictionary, identity is "the characteristics determining who or what a person or thing is". The Cambridge dictionary, however, defines it as: "who a person is, or the qualities of a person or group that make them different from others".

Additionally, Fearon (1999, p.2) distilled the meaning of identity from the analysis of both the current usage in ordinary language and social science discourse. He argues that the term identity is presently used in two senses: social and personal. In the former sense, he defines identity as "a social category, a set of persons marked by a label and distinguished by rules deciding membership and (alleged) characteristic features or attributes”. As for the second sense of personal identity; "an identity is some distinguishing characteristic (or characteristics) that a person takes a special pride in or views as socially consequential but more-or-less unchangeable”. Lynch (1960, p.8) interprets the identity of an object as "its distinction from other things, its recognition as a separable entity. This is called identity, not in the sense of equality with something else, but with the meaning of individuality or oneness". Brislin (2012) emphasises that the definition of identity could be either tight or loose, nevertheless it endows a sense of survival: "What is identity, that ephemeral and quixotic thing? Draw it too tightly and it is a noose: a boundary marker that defines the separation between individuals or between one group and another; a blunt weapon of differentiation that fuels rippling scales of dispute from neighbourhood argument through to Xenophobia and war. And yet draw identity too loosely and we no longer feel the connection between people and place..... Ironically, that 
which sustains us might also destroy us. But there is no doubt that a sense of identity is essential to survival - of individual, family, group and neighbourhood" (Brislin, 2012, P.8). Moreover, identity is strongly linked to the memory as Bandyopadhyay and Montiel (2013, p.xiv) emphasise: "memory is intimately connected with the construction of identity; it is with the memories we collect throughout our lives that we construct our sense of identity and belonging".Nevertheless, Fearon (1999) argues that although the use of the term 'identity' nowadays is a recent social construct that everyone knows how to use properly, it is still difficult to give a short and adequate summary that captures the range of its current meanings. This is because identity is often treated as something "ineffable and even sacred" (ibid, p.4).

Interestingly, when identity is linked to architecture it "goes beyond the visual appearance of the built environment and involves meanings of those built environments to the people who created them and the people who occupied them" (Salama, 2005, p.77). This is because architecture plays a key role in expressing the socio-cultural and political identities through its spatial, physical and representational dimensions (Bandyopadhyay \& Montiel, 2013). "While the extent to which architecture still retains the ability to express identity in today's schizophrenic, globalised world is debatable .....its role nevertheless continues to be accepted" (ibid, p. xiv). This is particularly important when an environment possesses a unique character it may be safe to say that this environment has an identity. (Salama, 2005) He elaborates that "an environment may be unique due to the use of certain unique forms that are to be found in this environment and nowhere else" (ibid, p.79).

However, it could be argued that there are places where the architecture does not have the ability to express any identity, but a chaotic image of different immature and contested identities. An example of these places is Khartoum, the capital city of Sudan with its urban fabric that represents buildings from various styles, heights, colours and materials. The combination of these give the impression that the situation is not only fluid but also uncontrollable. Consequently, it formed an intriguing example to explore in this research which could also be generalized to similar contexts like Khartoum.

As a first step to achieve this, the possibility of exploring the issue of architectural identity was reviewed in the literature. While architectural identity is about the physical character, personal meanings, memories and the sociocultural and political identities, the existence of all these dimensions in the definition of identity made it a loose and fluid issue that could be described as not only complex but also, an ambiguous and non-definable issue.

\subsection{Ambiguity and complexity of the issue of identity}

Identity is a complex issue because it stems from numerous determinants such as those from social and political order (Zarzar, 2008). Those determinants are continuously changing, thus identity becomes continuously evolving and not static. Within this, it was important to look for Sudanese writers and intellectuals who discussed the issue of identity in the context of Sudan. Ali (2014), a Sudanese sociologist, on the contrary, argues that identity, in general, is about abstraction, stability and essence. It is unified and does not get affected by time or history. Therefore, he believes that it is not proper to be utilised as a tool to describe social, political or cultural phenomena such as the nation or to understand the society in general. To him, it is completely/wholly an ideological, political, non-scientific and above all an ambiguous tool, which he does not encourage to be used in scientific terms. Rather, he prefers the term 'character'. Consequently, Ali (2014) went on and investigated the illogical attempts of Sudanese government officials to re-interpret the Sudanese identity. He concludes that the current period of the government is the period of inability to solve difficult and real problems, and thus they are escaping the reality to what he calls: "artificial issues" such as identity, which he eventually describes as a "delusion".

However, the situation with architectural identity is slightly different as it cannot be easily claimed as an artificial issue. This is due to the fact that architecture is the mirror that reflects the state of the government, people and cultural and social dimensions. While the finding of the ambiguity and complexity of the issue of identity was reached in an early stage of this research; during the first round of data collection, it was important not to disregard it. The more the interviewed architects were unable to find interpretations of what could represent a local architectural identity in their architecture, the more it became important to address this complexity of architectural identity in order to propose important answers for the future of contemporary architecture in Khartoum.

Moreover, it was noted that in the experience of Norberg-Schulz in Khartoum, although in essence, he described the architecture of the place, he avoided mentioning the term 'identity' and preferred to use simpler terms such as 
'character' to describe the physical character of the place and the 'genius loci' to describe its spirit. He narrated that the genius loci of a place "is determined by what is visualised, complemented, symbolised or gathered" (Christian Norberg-Schulz, 1980, p.58). The genius loci is thus about the space articulation and character articulation. The latter includes building materials, colour, the degree of openness, and the kind of construction (see Figure 5.3). Within this, it could be argued that Norberg-Schulz's avoidance of the term identity resulted from his background as an architectural theorist and his deep realisation of the complexity of the issue of identity. Moreover, it could be related to the fact that he is an outsider who is unlikely to express the architectural identity of a place -because identity strongly relates to variables such as culture which are difficult to be fully grasped by a foreigner.

This finding coincides with Salama (2005, p.78) who deconstructed identity in certain issues as he argued: "the discussion of the issue of identity in general and in the Middle East, in particular, would be irrelevant if concepts such as imageability, legibility, Critical Regionalism and environmental meaning are not debated and somehow theorized". Hence, it was helpful to search in the literature for the definition of those topics to come closer to identity. Kevin Lynch has introduced the two terms: imageability and legibility in the early 1960s. On one hand, he interprets legibility as the apparent clarity of the cityscape and the legible city as a city "whose districts or landmarks or pathways are easily identifiable and are easily grouped into an over-all pattern” (Lynch, 1960, p.3). On the other hand, he defines imageability as "the quality in a physical object which gives it a high probability of evoking a strong image in any given observer" (ibid, p.10). Therefore, he argues that a highly imageable city would seem well formed, distinct and remarkable and does not necessarily imply something that is "fixed, limited, precise, unified or regularly ordered, although it might sometimes have these qualities. Nor does it mean apparent at a glance, obvious, patent, or plain" (ibid). Therefore, imageability is the quality of both the identity and the structure.

As for Regionalism; Ozkan (2007) agrees with Salama (2005) that identity is related to Regionalism. The former even stresses that it is very hard to talk about identity without going into Regionalism. This is because Critical Regionalism as a notion emerged as an alternative to Postmodernism with the aim of reintroducing the historical knowledge and cultural issues in design (Tzonis \& Lefaivre, 2003). Moreover, it could also be considered as "a reaction specifically to internationalism or implicitly to Modernism” (Ozkan, 2007, p.103). It called for rethinking architecture through the concept of the region. It is complementary rather than contradictory to trends toward higher technology and a more global economy and culture (Tzonis \& Lefaivre, 2003). Kenneth Frampton defines the fundamental strategy of Critical Regionalism as: "to mediate the impact of universal civilisation with elements derived indirectly from the peculiarities of a particular place” (Frampton, 2002, p.21). Therefore, Regionalism is strongly tied with the characteristics of each particular region, which include aspects of society such as culture, aspects of life and prevalent modes of expression, and the natural environment, which includes climate and topography (Ozkan, 2007). It is thus through these aspects appears the strong link between identity and Regionalism. The difference is that Regionalism has been well defined as a theory with certain requirements and principles such as: resisting the various forms of hegemonic, universal and standardising structures that would diminish local differentiation (Canizaro, 2007), that the response to local conditions is more likely to be by necessity and not by choice and that it is a living concept that must grow and change just as regions must be continually re-described (ibid). On the contrary, architectural identity does not have defined principles; it could be the identity of the architect when recognizing his designs as a kind of brand or it could be about reinforcing the identity of an existing place (Zarzar, 2008). Additionally, identity refers to perception and it differs from a person to a person on how they perceive a certain building (ibid) Moreover, identity is about continuation and change and so is a person's life, thus his/her identity changes accordingly and will be reflected in the architecture through the time. Hence, "if a city loses its current identity, it is simultaneously creating a new one. Change in the direct environment over time is thus part of the creation of a new identity” (ibid, p.62).

In this regards and within these different scopes of literature highlighting the complexity of the issue of identity, it was relevant to assimilate that with the argument of Madanipour (1997) about urban design, in that it is a complex and at the same time ambiguous issue. He argued that the ambiguity of urban design stems from the fact that there are many disciplines and professions involved in it, which inevitably overlap with each other. Although some might argue that a degree of ambiguity offers a wider scope for innovation and development, others would argue that by clearly defining a subject we have denied it some flexibility (ibid). Therefore, he argues that it is difficult to claim to be engaged in urban design without properly defining it. Hence, he highlights that in the search for the meaning of urban design it is important "to remember to separate complexity from ambiguity" (ibid, p.364). He adds "we should be able to address complexity but we should also do our best to clarify ambiguities" (ibid). Similarly, this research utilises the same analogy to describe the issue of architectural identity. It argues that it is substantially important to define the architectural identity of a place instead of neglecting it. Individual efforts from architects are not sufficient, as it should also be at the planning and building legislation levels. Within this, the complexity should be addressed and the ambiguity should be confronted and clarified. Thus, it could be highlighted that confronting the complexity and ambiguity of architectural identity can be achieved by simplifying it, or more accurately, deconstructing it to simpler 
issues such as architectural character as those adopted by (Christian Norberg-Schulz, 1980) (Ali, 2014), imageability and legibility by (Salama, 2005) (Lynch, 1960) and Regionalism by (Ozkan, 2007).

By returning back to the context of Khartoum and in order to explore the issue of its architectural identity and confront its ambiguity within the scale of the research, the city centre of Khartoum (KCC) has been chosen as a case study. While the selection of the centre will limit the exploration to institutional architecture, it formed a rich context for exploration. This is because the centre is the place that witnessed the majority of the historical events through the history of Khartoum; from colonialism to independence in 1956 to the subsequent political regimes and the various unstable political situations between these periods. Thus, within these changes, and coupled with the rapid architectural transformation around the world during the last century (from Modernism to Postmodernism to Internationalisation), the architecture transformed dramatically in KCC and is now evident in its built environment. However, in order to narrow down the exploration, the period from the 1990s to the present was chosen from the architectural timeline of the city. This specific period has been selected because it has witnessed many changes that are yet to be documented and analysed in the architectural research of Khartoum's institutional architecture.

The exploration commenced with users of the city including architects, planners, architectural students and the general public through a series of interviews and focus groups. Interestingly, however, the exploration began with an overwhelming expectation that participants would be able to comment about the architectural identity -e.g.: the architects would have an explanation about the identity they create through their architecture- within the spectrum of those definitions from the literature. However, the findings were completely the opposite. Many participants asked to re-think the word identity; specifically Sudanese identity, and questioned what could represent the Sudanese identity in the architecture. On the other hand, some seemed to answer without precisely identifying which dimension of architectural identity they were explaining. This, in essence, relates back to the ambiguity and complexity of the issue of identity and consequently highlighted the necessity to explore it in a different way, which this research will try to achieve.

\section{Architectural identity of Khartoum city centre (KCC)}

Khartoum, the capital of Sudan, is a postcolonial city that despite becoming independent 60 years ago, has an architectural identity that is yet to be defined. While Christian Norberg-Schulz (1980, p.137) has exuberantly described the genius loci of the place Khartoum, he criticised the architecture of the late 1970s arguing that: "the impact of the forces of 'modern life' starts to make itself felt... without slightest understanding of the genius loci”. The situation later became even worse; the period of the 1980s witnessed an opening up of the country following the new-found oil wealth resulting in bringing foreign interests in the country by the $1990 \mathrm{~s}$ who brought foreign materials with them and an alternative language and scale of buildings (O. Osman, Bahreldin, \& Osman, 2014 ). Therefore, the authors went even further to declare that: "Architectural production in the country is today characterized by imitation and a rootless character" (ibid, p.10).

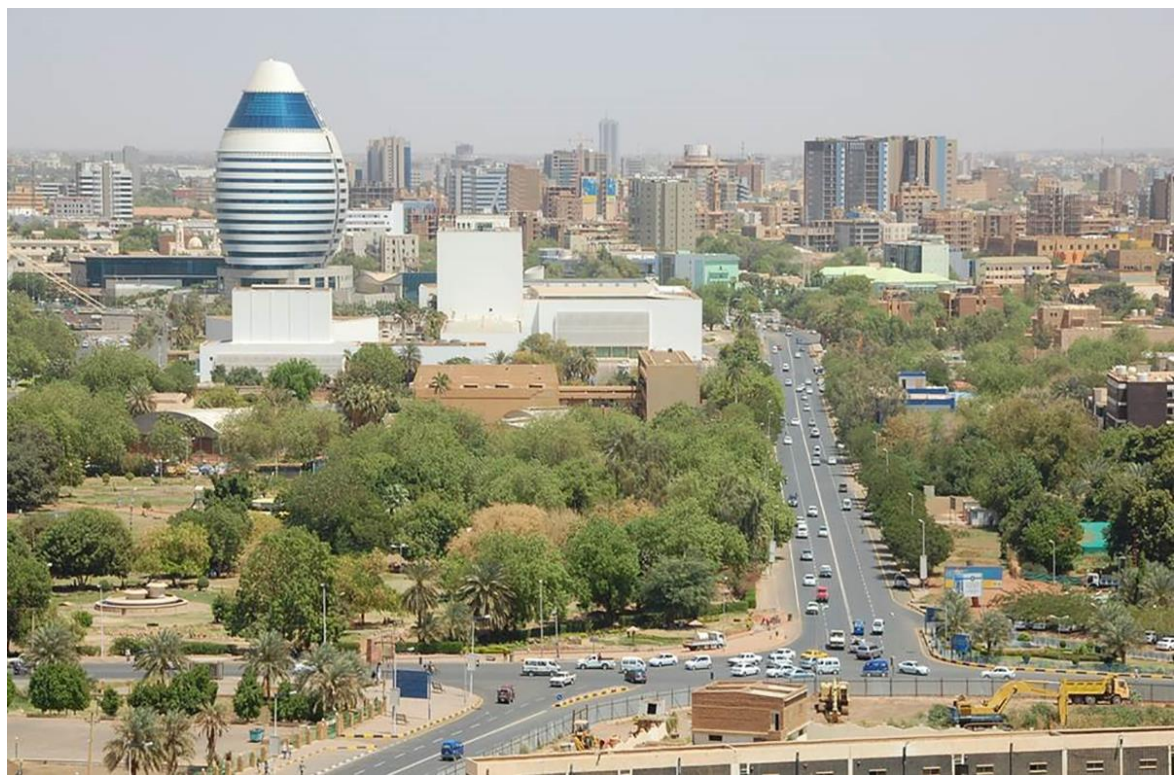

Figure -1: A contemporary scene of KCC. Source: https://www.pinterest.co.uk/pin/482800022528213215/ 
Based on this, it was thought to examine firstly: why there appears to be something missing in Khartoum's architectural spirit and the general reasons behind its so-called "rootless character". Apparently, this issue seems to be almost neglected and has not been convincingly studied in recent architectural research in Khartoum. There appears to be an omission in investigating and considering this gap, especially of the period from the 1990s to the present. Therefore, the research commences the exploration of Khartoum's architecture by tackling the issue of its architectural identity. Architectural identity in this sense was chosen as the issue that would be inclusive in overarching the issues of genius loci and architectural character mentioned by (Christian Norberg-Schulz, 1980) and (Omer Osman, Osman, \& Bahreldin, 2011).

However, with Khartoum being a newly emerging city that was established only 120 years ago, it could be considered as in the period of searching for its architectural identity which is still under construction. Consequently, one early notable finding about architectural identity in Khartoum was that architects had different interpretations of the issue of 'Sudanese architectural identity' in the current contemporary institutional architecture of KCC and thus, they had different representations. While some consider that it should be a local Sudanese identity with elements derived directly from Sudanese local culture(s) and traditional architecture, others consider it should be an Islamic identity because Islam is at the heart of the Sudanese culture and others believe that it should be an international identity that responds to forces of globalisation. Paradoxically, within each of these three opinions, there were other interpretations of how these approaches to identity could be achieved.

This highlights that Khartoum's architecture lacks the collective voice of architects that would carefully think the representation of the local Sudanese architectural identity in the architecture. Evidently, through interviews conducted with 26 architects with key roles in the architecture of Khartoum, it was found that efforts and discourses that respond to the current architectural identity were minimal and individualistic -as only three out of the 26 architects are trying to create a local identity that is derived from traditional architecture. The other majority were aiming and focusing on international globalised architecture. Nevertheless, the exploration will consider that forces of globalisation are inevitable and unavoidable in a rapidly urbanising context like Khartoum. While one could question the necessity of defining a certain Sudanese architectural identity in a rapidly changing world and specifying certain urban and architectural character, it nonetheless remains an inevitably important issue for the need for identification in one's own city and recognition amongst other cities in the world where s/he can always refer to a sense of belonging.

This finding was then followed by a notable common perception: that identity in Sudan will always remain an unsolved issue due to the cultural plurality of the country. While this fact is true, the perception is rather over-pessimistic, as a common quote was shared by many architects who were surrendering to the belief that: "we are living in a dilemma of a lost identity". As a result, this perception had affected the practice of architects in their approaches to design and oriented it towards an exploratory manner in expressing culture in the institutional identity, whereas some would disregard expressing the cultural symbolism altogether, those who would express it, show the different cultural representations that reflect the cultural plurality of Sudan. At the other end of the spectrum, others approached expressing culture through locality by adopting local materials and techniques in their designs.

On one hand, the presence of these various trends to express local identity in the architecture of Khartoum represents the lack of collective consensus onto the extent to which history and culture can be utilised into the contemporary institutional identity. This is why Bandyopadhyay and Montiel (2013).emphasise that critical positions in architectural identity discourse need to deal with such a volatile and chaotic situation of architectural identity. Yet, on the other hand, the appearance of these various trends is a natural process to search for identity because originally debates on 'local identity' came into prominence during the 1980s, when concerns arose from deep crisis confronting the traditional foundations of culture (Herrle, 2008). This crisis was mainly fuelled by the realisation that modernism had failed to deliver on its promises and aesthetics coupled with the disappearance of centralised institutions and collective minds as societies move through globalisation (ibid). Thus, it is possible to even argue that these different architectural trends are appearing very late in Khartoum and should have appeared earlier. Yet, in a context like KCC, issues such the unstable political situation and rapid urbanisation are considered far more serious problems than creating a local architectural identity, nonetheless, controlling those existing approaches to contemporary identity. Inevitably, architectural identity in these contexts, should not be a mere expression of the social and cultural peculiarities of the present time only, but it should also be an instrument to resist the destructive effects of globalisation (Bandyopadhyay \& Montiel, 2013).

In this regard, El-Sheshtawy and Abul Nagga (2000) argue that in a world now dominated by forces of globalisation, the common discourse on the identity crisis needs to be reconsidered. They believe that a co-existence model can be 
applied by taking into account the forces of modernisation and at the same time responding to the traditional elements in society. However, Mahgoub (2007) argues that in many developing countries architectural identity can hardly be localised since in many places identity entails composite patterns with more than one identity. Derakhshani (2012, p.31) agrees with this and questions: "How can multiple layers of identity be located within architecture? How can the architecture of each society become the true representation of its complexity?". Therefore, to explore and analyse these identity models it seems inadequate to explore only the 'local architecture' as it does not reflect the dynamic nature of the emergence of local identities in those contexts (Tzonis \& Lefaivre, 2003). Consequently, Derakhshani (2012) chooses a more 'inclusive' approach, rather than an 'exclusive' approach to exploring architectural identities which can successfully represent the plurality in these contexts. In this sense, he classifies the approaches to identity as:

- Reclaiming the local: through careful borrowing of elements from rich architectural traditions and reuse them to re-create the 'new local'.

- Appropriating the local: when the public and users reinterpret projects in a manner that is different from that which the architect had in mind and find other merits in the architecture (ibid).

- Inventing new identities: in newly emerging cities, which might not have rich traditional architecture, through strong, place-specific buildings to represent the country internationally.

The review of this literature has thus highlighted that exploring architectural identity in Khartoum has to be in an inclusive approach that would accommodate the extreme plurality of the community and somehow allow for a coexistence model. Therefore, similar to Derakhshani's (2012) classification on the approaches to identity, the approaches of architectural identity in KCC will be listed below. Nevertheless, listing these approaches alone could still be considered as fluid and largely subjective, exploration of the issue of architectural identity. Thus a participatory evaluation of these approaches was conducted with participants as users of the place KCC who through their visual and interactive experience with the architecture of $\mathrm{KCC}$ were able to interpret architectural identity through meanings, memories, socio-cultural dimensions, political dimensions and most importantly, the physical architectural character; that is exploring architectural identity through the experience of place (see Figure 2). These dimensions could be named as the variables of architectural identity which are both tangibles (character) and intangibles (meanings, memories, socio-cultural dimension and political dimension).

Yet, with the aim of confronting the complexity of architectural identity, this paper will aim for the more objective exploration for architectural identity and thus it will focus on listing the physical characteristics and features of the architecture of each of the identified approaches, evaluate them and discuss their representation of the sense of identity according to users of the place as follows:

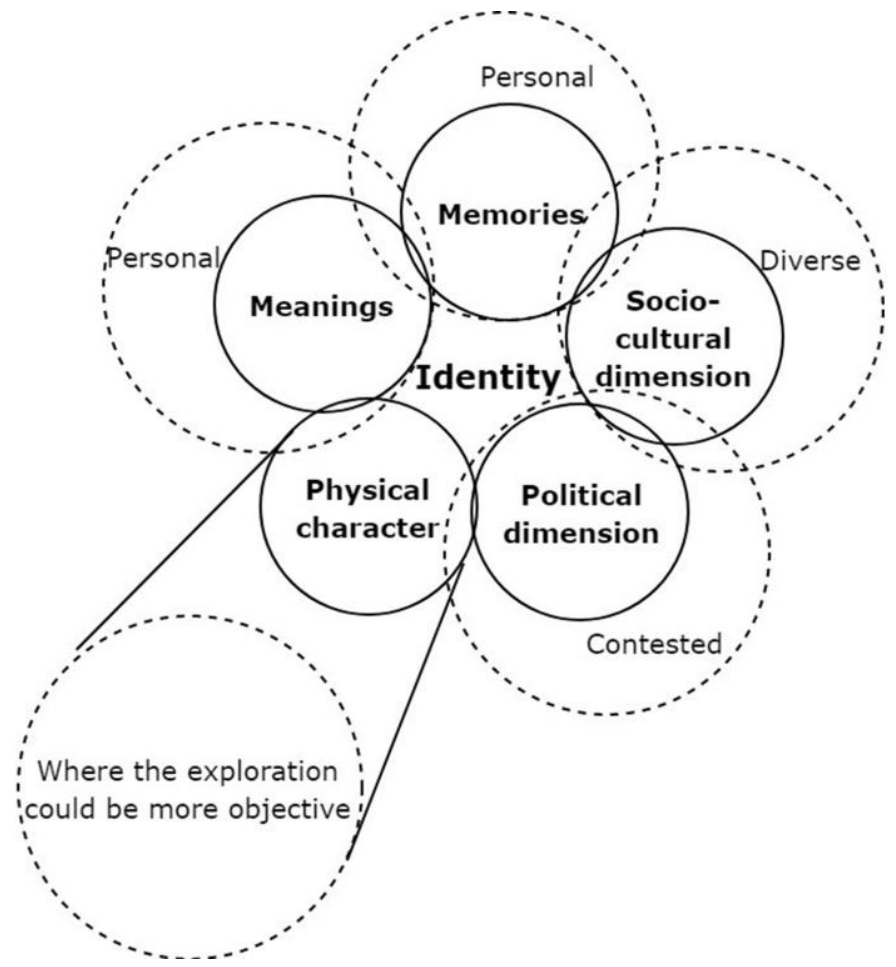

Figure 2: Variables of architectural identity with the physical character as the focus of this research. 


\subsection{Imposing new identities}

In Khartoum, the international style and globalised architecture have recently been promoted by the National Islamic Front government as its new image in the contemporary institutional architecture of KCC (Interviews F \& M, 2017) and (Centecs \& Meffit, 2008) as a replacement for the Islamic authentication movement that it imposed in the early 1990s. Nevertheless, coupled with economic limitations, response to the forces of globalisation and internationalisation, clients' preferences, and an immature exploratory architectural practice, this has resulted in an uncertain contemporary institutional architectural identity and an architecture that is based on an obsessive search for 'newness' as referred to by Pallasmaa (2012). This excessive modernity represents an implicit denial of the country's past evident and the urge to completely wipe and reformulate its history (A. Osman, 2002).

In addition to the governments' ideological image about the institutional architecture of Khartoum, this excessive newness is also supported by private developers who copy new visions from different places and paste them in their architecture. In a way, they are imposing their dreams on the architects under the label of promoting Khartoum to the global market. Therefore, they end up requesting projects that are either excessively modern or incorporate architectural features borrowed from other cultures. This concurs with Derakhshani (2012, P.30) who explains that "the speed of transformation in society has led to a disjoint; shifts in tastes and values have introduced new forms of commercial and retail structures". Similarly, in KCC the architectural transformation reflects a relatively dishonest transformation as it is driven by the imposed image on the architecture. Therefore, architects are being put under pressure to create an architecture that represents that image. Consequently, the new built institutional architecture is aesthetically striking, regardless of the physical context. While Adam (2012, p.176) argues that "architects are the agents of the symbolic visual markers of identity and, at the top of their profession, have been instrumental in major changes in the built environment", this role is yet to be implemented in Khartoum. Within this, the observed architectural features of this approach were (see Figure 3):

- Expensive materials (cladding) and shiny colours

- Monumental Landmark buildings

- Freestanding Isolated glass buildings

- \%100 occupation of the plots

- Invasive buildings

- Solid east and west elevations

- Minimum link to the natural landscape

- Unjustified utilisation of architectural features to enforce beautification

- Imported architecture (representing features borrowed from other countries to copy their identity especially in projects with foreign private developers)

While some of these features are prerequisites for the expressive quality required for the institutional architecture based on C. Norberg-Schulz's (2000) argument that institutional building's features ought to be treated and organised in a systematic and expressive way, some of them are illogical and undermine the sense of identity. This is because the word identity itself always relates to the deep unconscious links to what is local or cultural that provides a sense of rootedness and belonging. Therefore, characteristics such as monumentality, isolation and materials that do not relate to the place provide a sense of alienation rather than rootedness and are thus far from providing a sense of identity that local people feel belonging to. 

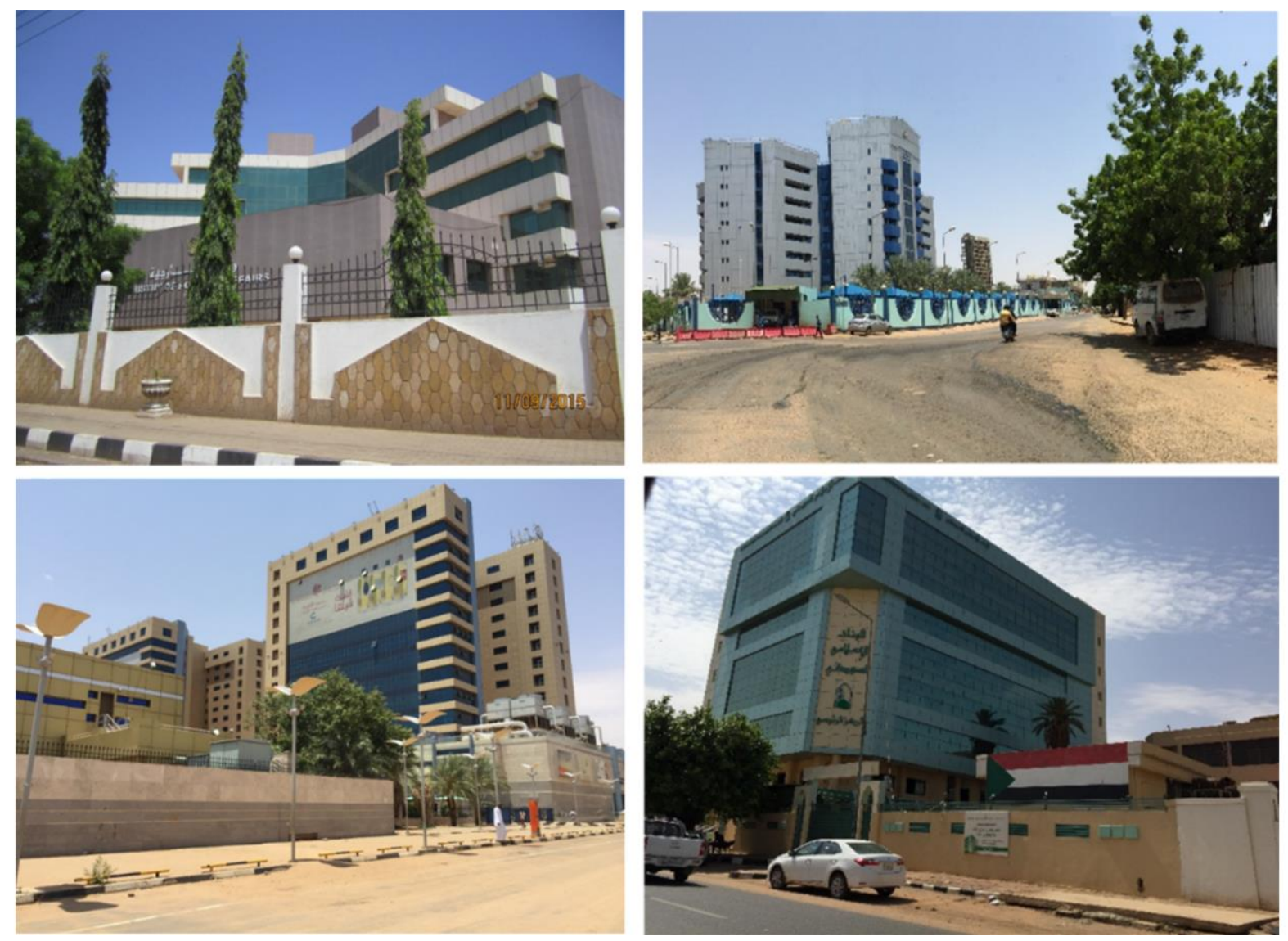

Figure 3: Examples of buildings from Imposing new identities approach showcasing the architectural characteristics. Source: the Author

\subsection{Islamising the Sudanese identity:}

Islamising the Sudanese institutional architectural identity in Khartoum appeared as the phenomenon that represents the naïve attempts to represent the notion of Islamic authentication that was adopted by the National Islamic Front government who realised that it is extremely difficult to achieve an architectural identity in such a plural community like Khartoum. Therefore, they chose Islam as the shared accepted factor that can be imposed to unify the architecture, yet deployed it only on the surface of the buildings. The series of observations in KCC captured those attempts and highlighted that their naivety stems from adding elements to superficially impose the Islamic identity. The most common feature, however, is the Arch, which can be found randomly, added in many boundary walls or gates of the governmental institutional buildings. Today is a phenomenon they still persist in the contemporary institutional architecture of KCC and in the capital as a whole (See Figure 4 ). Features that represent this approach are:

- Buildings and boundary walls with borrowed Islamic arches and ornaments

- Imported Islamic arches. 

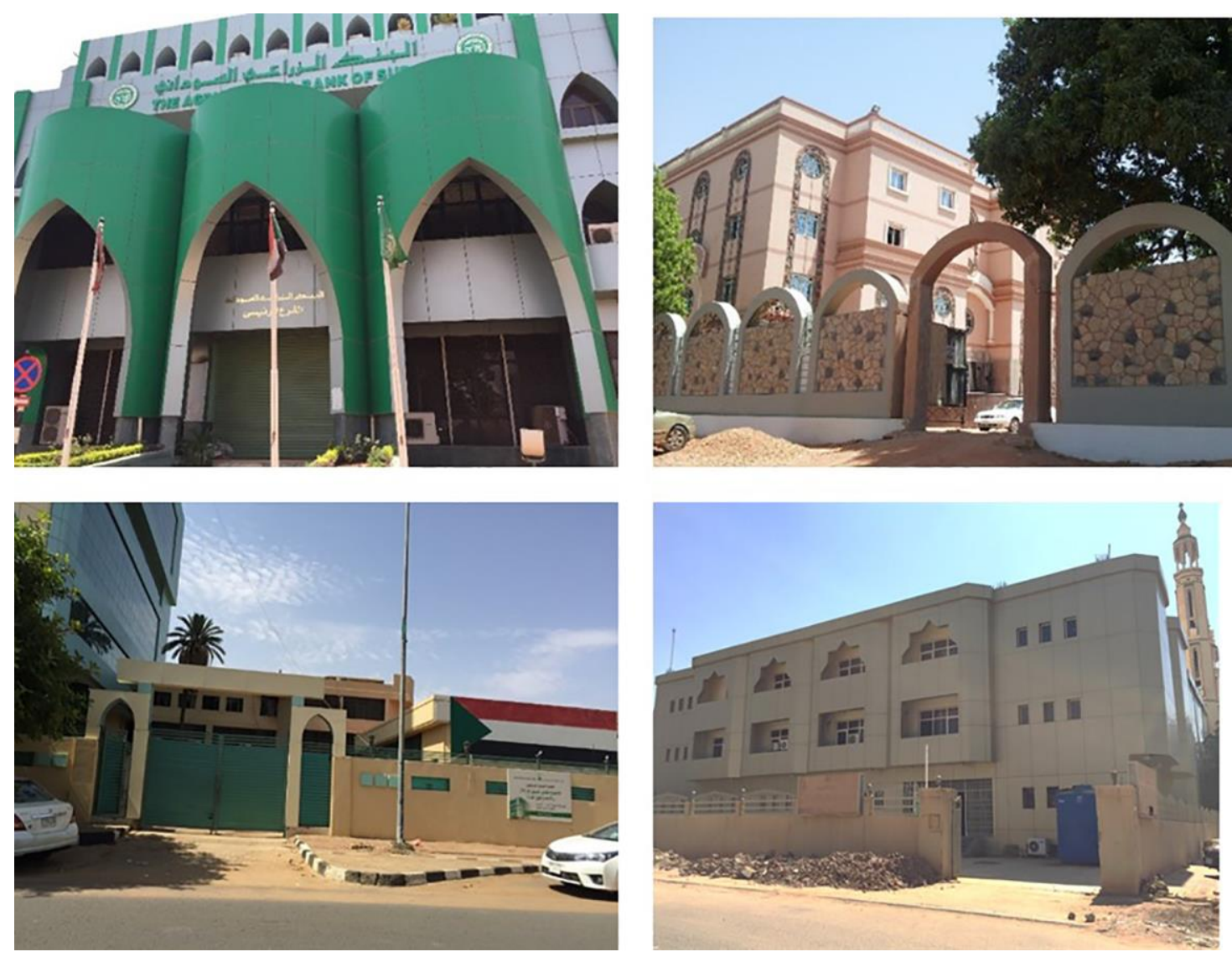

Figure 4: Naive attempts to impose an Islamic institutional architectural identity in KCC following the Islamic authentication notion. Source: The Author

\subsection{Reclaiming the local: A different promise?}

This approach to architectural identity relates to the efforts of architects who are attempting to revive a sense of local identity in the contemporary institutional architecture of Khartoum. The term 'reclaiming' is adopted from Derakhshani (2012) who described it as the careful borrowing of elements from traditional architecture and their reuse to re-create the 'new local'. In Khartoum, interviews with architects revealed that attempts to reclaim the local are minimum as only three out of 26 interviewed architects with key roles in the architectural practice in Khartoum were expressing a consideration to reclaim a local identity through showing significant sensitivity to the surrounding place and its particularities. Their approaches to this reclamation are either by direct borrowing from traditional architecture to deliver an explicit symbolism or an abstraction from traditional architecture to deliver an implicit symbolism; a metaphor, which are both commonly adopted approaches in Postmodernism to endue buildings with meanings. They, moreover, agree in certain aspects such as the use of local materials and low-rise architecture. The approaches to reclaiming a local institutional architectural identity as observed are as follows:

- Responsive approach

- Abstractive approach

- Eclectic approach

The first two approaches are relatively similar, as they abstract from the traditional architecture to deliver an implicit symbolism. They depend on appreciating the richness of natural resources in Sudan and use them as local materials; such as timber, bricks and different types of stones from different parts of Sudan. Within this, they bring the philosophy that: "the expression of materials is the visual symbol of the building" (Interview 2016). As for the Eclectic approach, it adopts the philosophy of reviving the Sudanese heritage in contemporary architecture through a direct borrowing to achieve an explicit symbolism. This approach adopts the philosophy that in order to revive history in the architecture, and to establish a sense of belonging to a Sudanese architectural identity, it is acceptable to eclectically borrow elements from the Sudanese architecture in different parts of Sudan such as arches from Nubian ${ }^{1}$ and colonial

\footnotetext{
${ }^{1}$ Nuba is a region that spans between southern Egypt to northern Sudan and is considered as a culturally and architecturally very rich region.
} 
architecture, Mashrabia ${ }^{2}$ and ornaments such as the Nubian Triangular ornaments and to employ them in contemporary buildings.

The main characteristics of the architecture of these approaches include simplicity of forms, linearity, strong indoor/outdoor spatial integration, incorporation of contemporary structural materials (viz,.steel) with local materials, shading and protection from severe climatic conditions and considerable integration within the surrounding urban fabric. This latter quality specifically is the essence of these approaches as they create buildings that mingle with their place. Consequently, their approaches to institutional architecture are more liberal in freeing the building and linking it to the surrounding, either visually or experientially as opposed to the freestanding isolated institutional buildings of the previous two approaches. Those approaches thus, emphasise that local architectural identity is not only visual but to a large extent experiential. Unfortunately, however, these approaches are rare in KCC as being only adopted by private individual architects in small private projects mostly outside KCC (see Figure 5). The observed features of these approaches were :

- Rectangular forms

- Low rise heights

- Local building materials

- Earthly colours

- Well-ventilated elevations (through verandas, recesses and openings )

- Shaded elevations (through verandas, recesses and small openings).

- Landscaping well integrated with the building

- Outdoor spaces well linked to the surrounding urban context'

- Symbolic cultural elements borrowed from different parts of Sudan.

- 'Arches': through arches that are copied from different parts around Sudan such as the symbolic Nubian arches, from both colonial architecture and Islamic architecture.

\footnotetext{
${ }^{2}$ Mashrabia: is an architectural element that characterises Arabic architecture. It is a wooden decorated bay that encloses the windows ex ternally to provide privacy. As a feature it is being borrowed from the architecture of Suakin ${ }^{2}$ in the Eastern part of Sudan.
} 

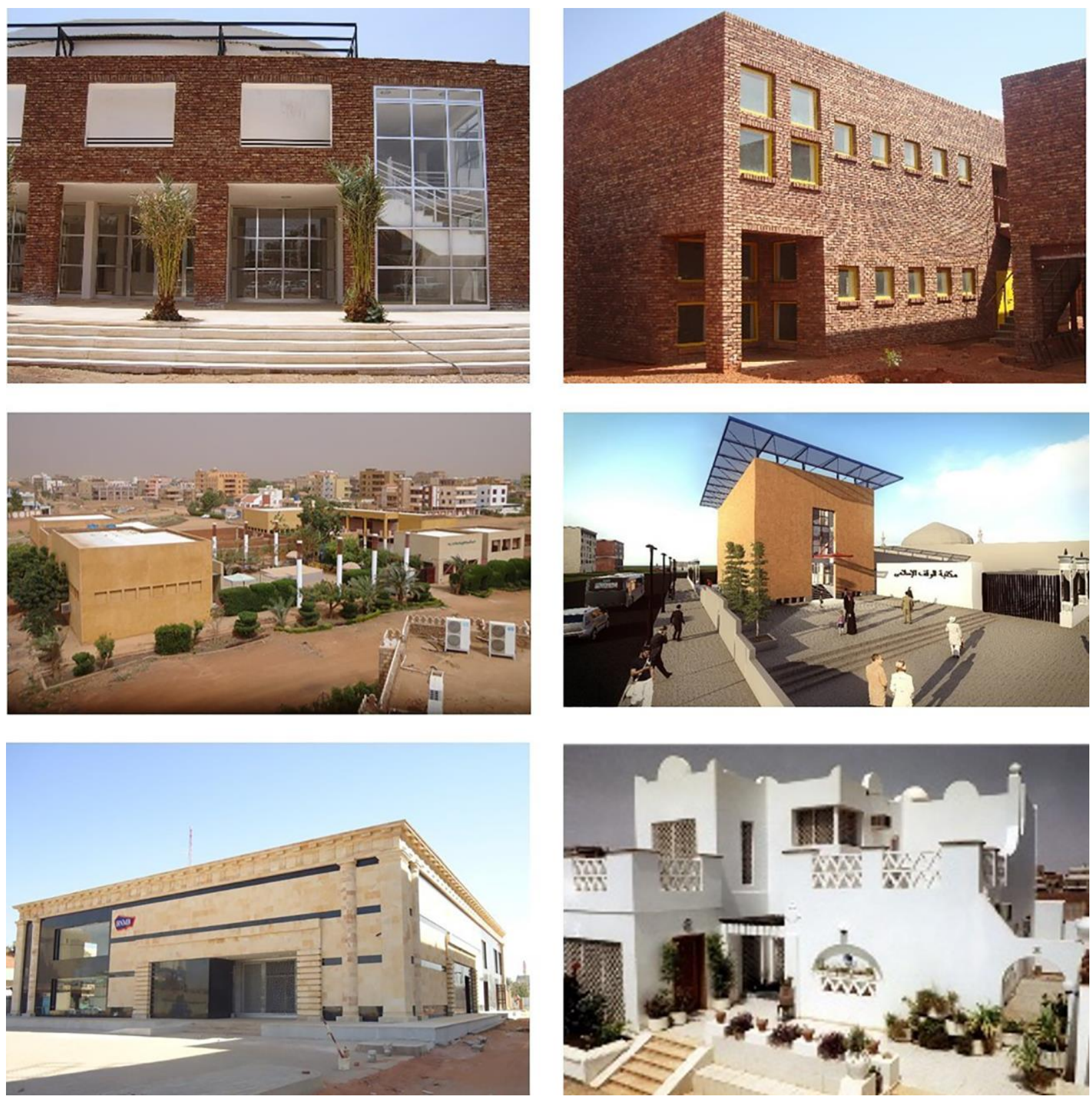

Figure 5: Approaches to reclaim local identity in Khartoum: Responsive (above), Abstractive (middle) and Eclectic approach (below). Sources: Hayder A.Ali Architects, Octantis architects and Ishkanes architects respectively.

\section{Discussion:}

It could be argued that both the Responsive and Abstractive approaches could be described as Modern Regionalism or Regional Modernism, which Salama (2005, p.82) defines as: "the incorporation of regional visual attributes into modern technology, where the interpretation of the past takes place to form a contemporary image”. Ozkan (2007) also explains the term and from his definition, one can fairly emphasise that on one hand, such efforts are related as Modern because they respect the qualities of building materials and present functional justifications for forms that constitute buildings. On the other hand, they relate to Regionalism because in essence they utilise the regional qualities in their architecture and are unlike Internationalism which demands to reduce the building to skin and bones (ibid). According to Ozkan (2007, p.109), these approaches could be labelled "Abstract Regionalism", which he asserts: "mainly incorporates the abstract qualities of a building, for example, massing, solids and void, proportions, sense of space, use of light and structural principles in their reinterpreted form". As for the Eclectic approach, it could be labelled as what Salama (2005, p.81) calls "Historicism or Historical Revivalism”, or as what Ozkan (2007, p.104) calls "Vernacularism" and defines as "bringing a new and contemporary existence to vernacular forms and spatial arrangements". Nevertheless, the applicability of this approach in institutional architecture seems to be the most controversial as the validity of borrowed historical features in a contemporary institutional building is rather more debatable. 
With the real essence of these approaches abstracted from the local forms of the traditional Sudanese vernacular architecture (see Figure 6), participants emphasised that a cultural revival and place attachment could be achieved through these approaches. However, this is yet to be achieved in KCC as these approaches are evidently absent from $\mathrm{KCC}$ and are being adopted by a few individual architects in private projects. Inevitably, these approaches, if adopted, can give Sudanese people the opportunity to reconstruct missing links to their local architecture in the contemporary institutional architectural identity despite the cultural debate on some of the symbolic representations. And, if applied in $\mathrm{KCC}$, they could provide a better amalgamation with the existing colonial fabric due to their nature of adopting the same local materiality and heights adopted in colonial architecture.
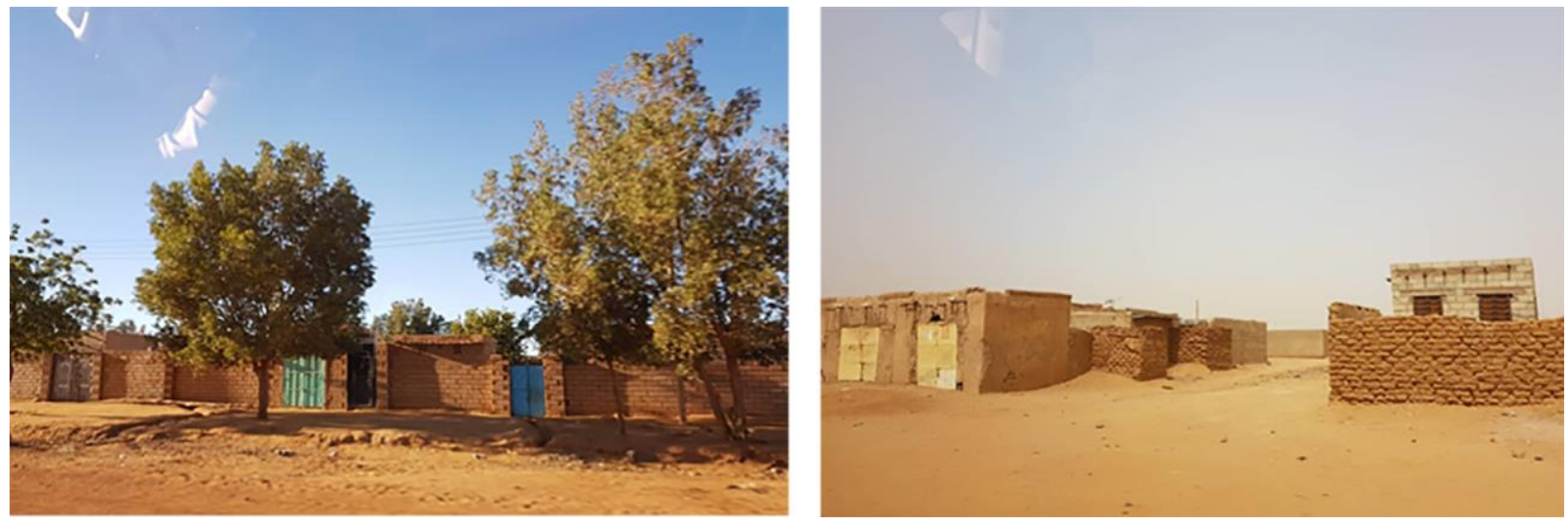

Figure 6: Typical scene in traditional vernacular neighbourhoods in Khartoum with the houses as simple cubical forms. Source: Gamal Hamid's archive.

Despite this link to vernacular architecture, sense of rootedness and response to the place, this type of identity is not always applicable to new emerging city centres. This is due to their heights and scale that do not accommodate the capacities of the contemporary institutional architecture of city centres nor do they satisfy their expressive qualities. This was emphasized by the different categories of participants in evaluating and prioritizing some of the main features of these approaches such as the heights and the simple rectangular forms as the least applicable to the identity of KCC. On the other hand, they highlighted other intrinsic qualities such as well-ventilated elevations (through verandas, recesses and openings), shaded elevations (through verandas, recesses and small openings) and landscaping well integrated with the building as unique intrinsic qualities that need to be concretised in the architectural identity of KCC more than any other visual cultural representations. Hence, this participatory evaluation in KCC unconsciously disregarded the search for the visual cultural representation of identity and instead called for revealing and reemphasising the architectural features that present unique experiential qualities and response to the weather. As an example of this, the arcaded porticos of KCC's colonial architecture (see Figure 7) were considered as the essence of the place due to their unique experiential quality. Thus, their re-emphasisation could nurture the local character and act as symbols for the institutional architectural identity of KCC. 

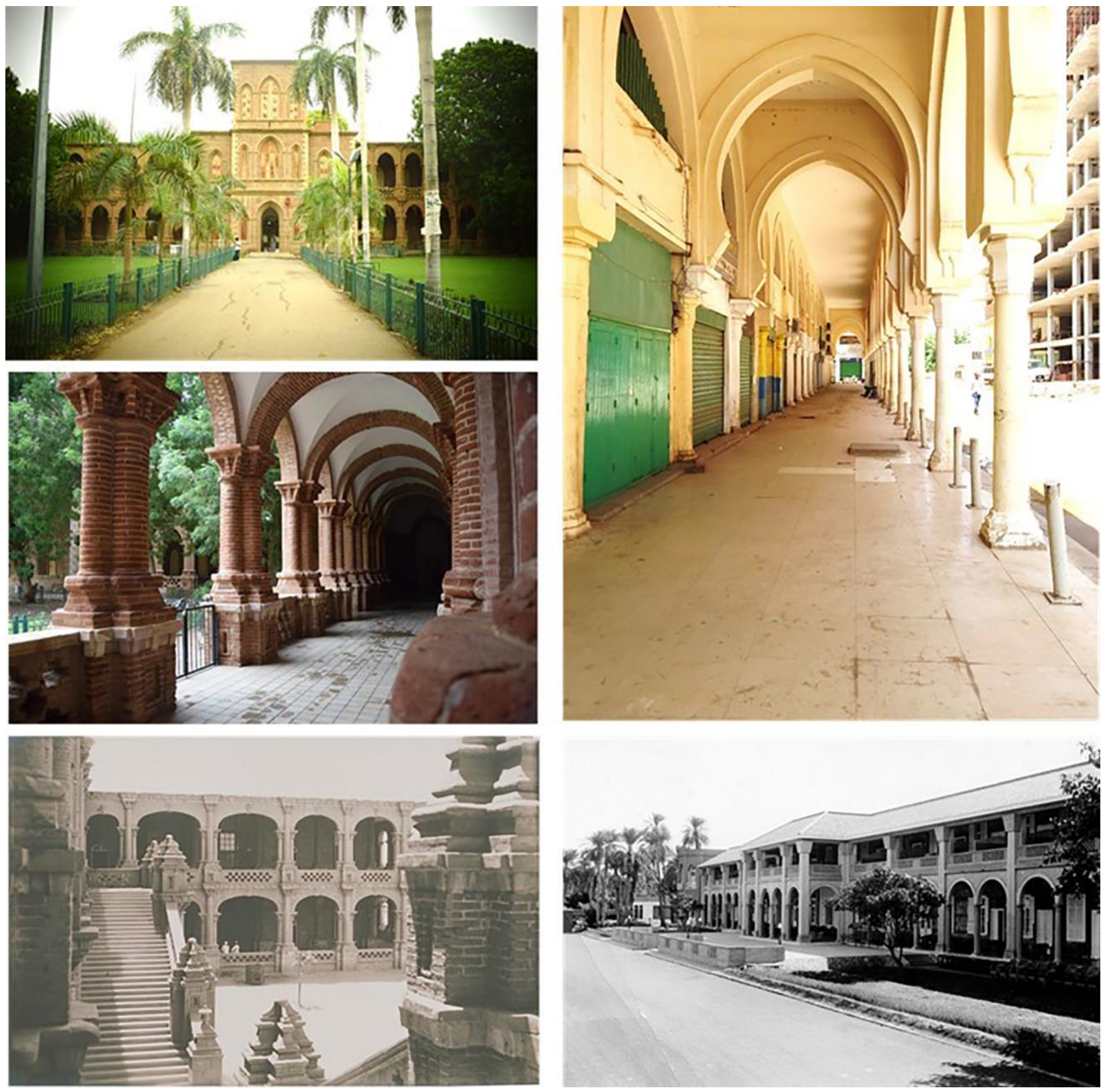

Figure 7: Archaded porticos in colonial architecture have been identified as the essence of the architecture of KCC in the participatory evaluation process. Source: the Author

Hence it could be highlighted that these required architectural qualities embody a sense of rootedness that is more experienced and lived rather than being merely visual. Thus, architectural identity from an experience point of view -through participatory evaluation of users of the place- is not only visual but also experiential. Consequently, the visual-cultural search for architectural identity, alone, is no longer valid, and it should be towards achieving the unique qualities that are being identified through the participatory evaluation by users of the place.

Reaching this proposal of revealing the unique architectural features of each approach and consider the idea of enhancing the architecture of KCC through reintroducing and strengthening these features could result in what Brislin (2012, p.9) names as the 'spirited architecture of place' which he supposes as an "architecture that belongs to the soil within which it is sited, and which belongs to its people too. They are grasping points that resist neutralising tendencies that stand fast against sweeping forces that are greater than individuals". Here, the search changes from debating on how to achieve an architectural identity and the consequent cultural debate to valorising and re-emphasising its unique existing features (see Figure 8). In addition to valorising the unique features, there are essential qualities in any built environment that ensure a better-enhanced architecture and if they exist, they will maintain an enhanced spirit of the place. Those qualities are as follows: 
- Integrating the building with its surrounding ( e.g.: removing boundary walls, providing foregrounds in front of the buildings and creating buildings that are more open to the environment).

- Provide walkability (e.g.: shaded walkways).

- Response to the climatic conditions

- Sustainability (e.g. the use of local building materials and colours).

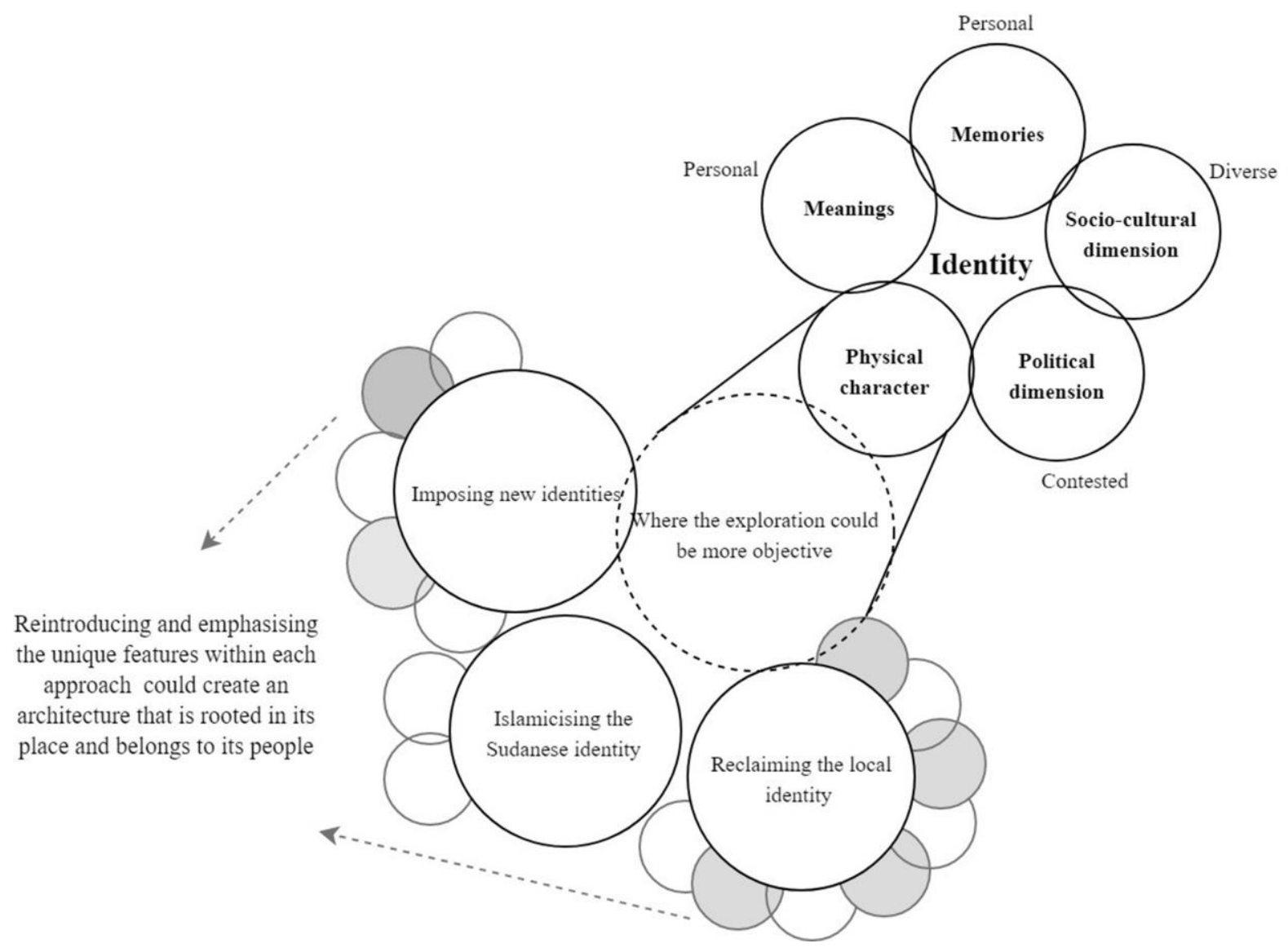

Figure 8: The objective exploration of identity has allowed revealing the unique qualities within each approach

\section{Conclusion:}

This research explored the issue of architectural identity in the context of Khartoum and focused in its centre KCC as a case study. With Khartoum being established only 120 years ago, it was found that architects' current approaches and endeavours are helping in shaping the base of its architectural identity and that architectural identity is still under construction. Nevertheless, the exploration resulted in documenting the different current approaches of identity in KCC and classified them in three main approaches: Imposing new identities, Islamicising the Sudanese identity and Reclaiming the local.

Additionally, the research emphasized the complexity and ambiguity of the issue of identity, which arises from the various variables that determine it such as meanings, memories, cultural, social and political dimensions and finally the architectural character. Accordingly, such documentation, alone, could not provide answers and solutions in a newly emerging city with a plural community like Khartoum and the issue will largely remain subjective.

Accordingly, this research addressed the complexity of the issue of architectural identity and proposed confronting its ambiguity through a more objective approach undertaken by a participatory evaluation of the physical characteristics of the three identified approaches of identity in KCC by the place's own users, that is, distilling architectural identity to its architectural character. It was found that through this objective evaluation, participants were able to look at the architecture of each approach in an abstract way as some physical characteristics and became able to evaluate, reveal the ones with unique qualities and discuss them in relation to identity. Through this objective participatory evaluation, 
users of the place were able to shift from debating the merely visual- cultural representations of architectural identity to emphasising the features that endue the architecture and its surrounding place with unique experiential qualities. Hence, the question of identity as merely a visual image becomes no more valid.

In a way or another, this method inevitably confronts the ambiguity of the issue of identity, simplifies and deconstructs its complexity into simpler more approachable issues of exploration.

\section{References}

Adam, R. (2012). Identity and identification: the role of architectural identity in a Globalised world. In H. Casakin \& F. Bernardo (Eds.), The role of place identity in the perception, understanding, and design of built environments (pp. 176-193). UK: Bentham Science Publishers.

Ali, H. (2014). In the laughter of fate (second episode): the delusion of identity (translated from Arabic). Retrieved from https://www.alrakoba.net/news-action-show-id-145714.htm

Bandyopadhyay, S., \& Montiel, G. G. (2013). Introduction: Beyond the (post)colonial fragmented identities in the age of globalization. In The territories of identity: architecture in the age of evolving globalization: Routledge.

Brislin, P. (2012, ). Identity, Place and Human experience Architectural Design 82, 8-13.

Canizaro, V. B. (2007). Architectural regionalism: Collected writings on place, identity, modernity, and tradition. New York, NY, USA: Princeton Architectural Press.

Centecs, \& Meffit. (2008). Khartoum structural plan (KPP5). Retrieved from Khartoum:

Derakhshani, F. (2012, Nov/Dec 2012). Appropriating, Reclaiming and Inventing Identity through Architecture. Architectural Design magazine, 220.

El-Sheshtawy, Y., \& Abul Nagga, M. (2000). Sustainable Urban Development in an Age of Globalization: Towards a co-existence model in Dubai, UAE. Paper presented at the IAPS 16, Paris.

Fearon, J. (1999). What is idenity (as we now use the word)? . Stanford University, CA.

Frampton, K. (2002). Towards a critical regionalism: Six points for an architecture of resistance. In Labour, Work and Architecture: Collected Essays on Architecture and Design (pp. (77-89)): London: Phaidon Press.

Herrle, P. (2008). Architecture and Identity? Steppenwolf and the carriers of change. In P. Herrle \& E. Wegerhoff (Eds.), Architecture and Identity (pp. 11-22). Technische Universität Berlin. : LIT Verlag Münster.

Lynch, K. (1960). The Image of the City. Cambridge, Mass. : MIT Press.

Madanipour, A. (1997). Ambiguities of urban design. The Town Planning Review, 68(3), 363-383.

Mahgoub, Y. (2007). Architecture and the expression of cultural identity in Kuwait The Journal of Architecture, 12(2), 165-182.

Norberg-Schulz, C. (1980). Genius loci: Towards a Phenomenology of Architecture. UK: Academy Editions

Norberg-Schulz, C. (2000). Principles of modern architecture: A. Papadakis.

Osman, A. (2002). Thoughts on the role of architects in two African contexts: The re-making of urban identity. Retrieved

from https://www.researchgate.net/publication/228837282_Thoughts_on_the_role_of_architects_in_two_Africa n_contexts_The_re-making_of_urban_identity

Osman, O., Bahreldin, I., \& Osman, A. (2014). Architecture in Sudan 1900-2014; An Endeavor Against the Odds. In G. Arbid (Ed.), Fundamentalists and Other Arab Modernisms: Architecture from the Arab World 19142014. Bahrain: Bahrain Ministry of Culture; Arab Centre for Architecture.

Osman, O., Osman, A., \& Bahreldin, I. (2011). Architecture in Sudan: The Post-Independence Era (1956-1970), Focus on the Work of Abdel Moneim Mustafa. Docomomo Journal, 1(44), 77-80.

Ozkan, S. (2007). Regionalism with modernism. In V. B. Canizaro (Ed.), Architectural regionalism: Collected writings on place, identity, modernity, and tradition (pp. 103 - 110). New York, NY, USA: Princeton Architectural Press.

Pallasmaa, J. (2012). Newness, Tradition and Identity. Architectural Design 82(6), 14-21.

Salama, A. M. (2005). Architectural identity in the Middle East: hidden assumptions and philosophical perspectives. In D. Mazzoleni, G. Anzani, A. M. Salama, M. Sepe, \& M. M. Simone (Eds.), Shores of the Mediterranean: Architecture as a Language of Peace (pp. 77-85). Napoli, Italy: Intra Moenia, .

Tzonis, A., \& Lefaivre, L. (2003). Critical regionalism: Architecture and identity in a globalized world: Prestel New York.

Zarzar, K. M. (2008). The Questions of Identity in Design. In K. M. Zarzar \& A. Guney (Eds.), Understanding Meaningful Environments: Architectural Precedents and the Question of Identity in Creative Design (Vol. 4): IOS Press. 